\title{
Insulin potentiates essential amino acids effects on mechanistic target of rapamycin complex 1 signaling in MAC-T cells
}

\author{
Virginia L. Pszczolkowski, ${ }^{1,2 *}$ ๑ Jun Zhang, ${ }^{1,3 *} \dagger$ Kayleigh A. Pignato, ${ }^{1}$ Emma J. Meyer, ${ }^{1}$ Madison M. Kurth, ${ }^{1}$ \\ Amy Lin, ${ }^{1}$ and Sebastian I. Arriola Apelo ${ }^{1,2} \ddagger$ ๑ \\ ${ }^{1}$ Department of Animal and Dairy Sciences, University of Wisconsin-Madison, 53706 \\ ${ }^{2}$ Endocrinology and Reproductive Physiology Graduate Training Program, University of Wisconsin-Madison, 53706 \\ ${ }^{3}$ State Key Laboratory of Animal Nutrition, College of Animal Science and Technology, China Agricultural University, Beijing, China 100083
}

\begin{abstract}
Different models of lactation offer conflicting evidence as to whether insulin signaling is required for AA to stimulate mechanistic target of rapamycin complex 1 (mTORC1) activity. We hypothesized that insulin potentiates essential AA stimulation of mTORC1 activity in the MAC-T mammary epithelial cell line. Here, our objective was to assess mTORC1 signaling activity in response to insulin and individual or grouped essential AA. Insulin and essential AA concentrations in the treatment medium ranged from normo- to supraphysiological, with insulin at $0,1,10$, or $100 \mathrm{nmol} / \mathrm{L}$ and essential AA at approximately $0,0.01,0.05,0.1,1$, or $3 \times$ reference plasma levels. Effects and interaction of insulin and total essential AA were tested in a $3 \times 5$ factorial design ( $\mathrm{n}=3$ replicates/treatment); insulin and the individual AA Leu, Met, Ile, and Arg were likewise tested in $3 \times 4$ factorials $(\mathrm{n}=4)$. As the remaining individual AA His, Lys, Phe, Thr, Trp, and Val were expected to not affect mTORC1, these were tested only at the highest insulin level, $100 \mathrm{nmol} / \mathrm{L}(\mathrm{n}=4)$. For all of these, linear and quadratic effects of total and individual AA were evaluated. Essential AA were subsequently grouped by their positive (Leu, Met, Ile, Arg, and Thr; TOR-AA) or absent-to-negative effects (His, Lys, Phe, Trp, and Val; NTOR-AA), and tested for interaction in a $2 \times 2$ factorial design $(\mathrm{n}=4)$, with each AA at its respective $1 \times$ plasma level, and insulin held at $100 \mathrm{nmol} / \mathrm{L}$. All experiments consisted of $1 \mathrm{~h}$ treatment incubation, followed by Western blotting of cell lysates to measure phosphorylation and abundance of the mTORC1 pathway proteins Akt (Ser473); ribosomal protein S6 kinase p70 (S6K1, Thr389); eukary-
\end{abstract}

\footnotetext{
Received May 19, 2020.

Accepted August 6, 2020.

*These authors contributed equally to this work.

†Current address: College of Animal Science and Technology, Northwest A\&F University, Yangling, Shaanxi, China.

‡Corresponding author: arriolaapelo@wisc.edu
}

otic translation initiation factor 4E-binding protein 1 (4E-BP1, Ser65); and ribosomal protein S6 (S6, Ser240/244). The Akt phosphorylation was overall increased by insulin, with a possible negative interaction with both total essential AA and the individual AA Leu. Total essential AA also increased S6K1 and 4EBP1 phosphorylation in an insulin-dependent manner. The individual AA Leu, Met, Ile, and Arg increased S6K1 phosphorylation in an insulin-dependent manner. Similarly, Met and Arg increased 4E-BP1 phosphorylation in an insulin-dependent manner. Histidine, Lys, Trp, and Val did not affect S6K1 phosphorylation. However, S6K1 phosphorylation was linearly increased by Thr and quadratically decreased by Phe. Relative to the phosphorylation of S6K1 when cells were incubated with no essential AA, the NTOR-AA group had no effect, whereas the TOR-AA increased phosphorylation to the same degree observed with all 10 essential AA. Overall, we have found that insulin is required for essential AA to stimulate mTORC1 activity in MAC-T cells. In addition, the AA responsible for the bulk of mTORC1 activation in MAC-T are limited to Leu, Met, Ile, Arg, and Thr.

Key words: essential amino acids, insulin, mTORC1, mammary epithelial cells

\section{INTRODUCTION}

Research on milk production often groups essential amino acids as a whole (Appuhamy et al., 2011a), by their structure (Doelman et al., 2015b), or by their uptake:output ratio in the mammary glands (Lapierre et al., 2007). However, such groupings do not consider the signaling roles these AA play in milk protein synthesis regulation. One pathway guided by AA signaling is that centered around the mechanistic target of rapamycin complex 1 (mTORC1). This complex is composed of the serine/threonine protein kinase mTOR and its binding partners: mammalian lethal with SEC13 protein 8, required for complex assembly; regulatory as- 
sociated protein of mTOR, a substrate-binding protein; Dishevelled, Egl-10 and Pleckstrin domain-containing mTOR-interacting protein, a regulatory protein; and 40-kDA proline-rich Akt substrate (PRAS40), a regulatory protein (Kennedy and Lamming, 2016). Among other metabolic and nutritional signals, mTORC1 is responsive both to certain AA and insulin (Appuhamy et al., 2011a; Appuhamy et al., 2012; Arriola Apelo et al., 2014a; Menon et al., 2014; Ma et al., 2018).

In the established molecular model of mTORC1 signaling, AA function to induce mTORC1 localization to the lysosomal membrane; insulin signaling is then required for actual mTORC1 activation through Rheb (Long et al., 2005; Sancak et al., 2010; Colaço and Jäättelä, 2017). The small GTPase Rheb is the final insulin-directed gatekeeper upstream of mTORC1 (Manning and Cantley, 2003). Two steps up from Rheb is Akt, a kinase central to intracellular insulin signaling (Burgering and Coffer, 1995) and promotor of insulindependent mTORC1 activity (Inoki et al., 2002). This model, wherein both AA and insulin are required to initiate mTORC1's anabolic activity, is generally supported by in vivo research in dairy cattle during established lactation.

In lactating cows, a milk protein synthesis response to infused AA has been shown to necessitate the coupling of insulin or starch, an insulinemic energy source (Mackle et al., 1999; Rius et al., 2010), with coordinated mTORC1 pathway activation apparent only in conjunction with starch infusion (Rius et al., 2010). However, at least one in vivo study has shown contradictory activation of mTORC1 activity and milk protein production, with diminished Lys supply increasing mTORC1 activity even as protein yield decreased (Doelman et al., 2015b). As well, in vitro work contradicts the model of coordination between insulin and AA signaling, and has indicated independent and additive effects of AA and insulin on mTORC1 signaling and protein synthesis (Appuhamy et al., 2011a). As such, there is still controversy regarding the role of mammary insulin signaling on the molecular mechanisms that regulate protein synthesis in dairy cattle.

Importantly, insulin secretion and sensitivity are dynamic throughout pregnancy and lactation, and so it is necessary to understand the physiological state under which insulin action is expected to occur. Although coordination of insulin and AA is likely the case during established lactation when the mammary gland is sensitive to insulin, during calving and in the transition period circulating insulin is at its nadir (Kerestes et al., 2009), and so too is insulin sensitivity (Debras et al., 1989). On the other hand, there is evidence that prepartum supplementation with AA such as arginine, an AA stimulatory to mTORC1 (Chantranupong et al.,
2016), can affect milk yield of the subsequent lactation (Chew et al., 1984), indicating a potential for prepartum priming for milk production regardless of the loss in insulin action at the time of calving.

To direct research toward the most promising nutritional interventions for lactating dairy cattle, it is critical that the cellular mechanisms underlying production responses are adequately established. With this goal in mind, we hypothesized that insulin potentiates EAA stimulation of mTORC1 activity in MAC-T, an immortalized mammary epithelial cell line (Huynh et al., 1991). Our objective was to assess the role of insulin on mTORC1 stimulation by total and individual EAA in MAC-T. Although the MAC-T cell line is not capable of synthesizing milk components, it has been used extensively in cellular signaling experiments (Appuhamy et al., 2011c; Appuhamy et al., 2012; Li et al., 2017), and we expect that the results of these experiments are sufficiently similar to normal mammary epithelial cell signaling so as to provide a foundation for guiding research in more complex systems.

\section{MATERIALS AND METHODS}

\section{Cell Culture}

The MAC-T cells (Huynh et al., 1991) were recovered from liquid nitrogen storage and grown as a monolayer in 10-cm tissue culture-treated dishes at $37^{\circ} \mathrm{C}$ and $5 \%$ $\mathrm{CO}_{2}$, in Dulbecco's Modified Eagle's Medium Ham's F-12 medium (DMEM/F12, Corning, Corning, NY) supplemented with $10 \%$ fetal bovine serum (FBS, HyClone, GE Healthcare, Chicago, IL), $10 \mathrm{mg} / \mathrm{L}$ insulin (Sigma-Aldrich, St. Louis, MO), $100 \mu \mathrm{g} / \mathrm{mL}$ streptomycin, and $100 \mathrm{IU} / \mathrm{mL}$ penicillin. At 80\% confluency, cells were collected by trypsin digestion (Corning) and seeded onto 6-cm dishes.

At $80 \%$ confluency, cells were washed once with sterile PBS and incubated $16 \mathrm{~h}$ in an FBS-, insulin-, and EAA-free starvation medium composed of DMEM/F12 (US Biological, Swampscott, MA), $3.56 \mathrm{~g} / \mathrm{L}$ HEPES, $3.7 \mathrm{~g} / \mathrm{L}$ sodium bicarbonate, $100 \mu \mathrm{g} / \mathrm{mL}$ streptomycin, $100 \mathrm{IU} / \mathrm{mL}$ penicillin, and $1.15 \mathrm{mmol} / \mathrm{L} \mathrm{NEAA} \mathrm{(Table}$ 1). Individual NEAA concentrations were selected based on compiled plasma level of total AA in lactating dairy cattle (Pösö and Lindberg, 1994; Meijer et al., 1995; Martineau et al., 2017), and the individual AA profile observed in milk proteins (Swaisgood, 1995). Following the starvation period, cells were treated as described below.

\section{Experimental Design and Treatments}

Cell density remained between 80 and $90 \%$ confluent following the starvation period for all experiments. All 
Table 1. Individual EAA and NEAA in starvation and experimental medium

\begin{tabular}{lcc}
\hline AA & $\begin{array}{c}\text { Total, } \\
\mu \text { mol/L }\end{array}$ & Percent \\
\hline EAA $^{1}$ & 162 & 5 \\
Arginine & 147 & 5 \\
Histidine & 374 & 12 \\
Isoleucine & 617 & 21 \\
Leucine & 470 & 16 \\
Lysine & 158 & 5 \\
Methionine & 247 & 8 \\
Phenylalanine & 302 & 10 \\
Threonine & 60 & 2 \\
Tryptophan & 464 & 15 \\
Valine & & \\
NEAA & 105 & 8 \\
Alanine & 89 & 7 \\
Asparagine & 182 & 14 \\
Glutamine & 66 & 5 \\
Glycine & 245 & 19 \\
Proline & 169 & 13 \\
Serine & 87 & 7 \\
Tyrosine & 13 & 1 \\
Cysteine & 71 & 6 \\
Aspartate & 233 & 19 \\
Glutamate & & \\
\hline
\end{tabular}

${ }^{1}$ Concentrations of EAA correspond to the 3,000 $\mu \mathrm{mol} / \mathrm{L}$ experimental medium used in the total EAA experiments, with the percentages remaining consistent with lower total EAA.

${ }^{2}$ Concentrations of NEAA correspond to the $1.15 \mathrm{mmol} / \mathrm{L}$ total NEAA concentration used across all experimental treatments.

experiments were performed in media containing 1.15 mmol/L NEAA (Table 1) for $1 \mathrm{~h}$ incubations, sufficient time for phosphorylation changes to occur (Foster et al., 2010). Experiments were terminated by washing plates with ice-cold PBS followed immediately by harvest with RIPA lysis buffer $(50 \mathrm{mmol} / \mathrm{L}$ HEPES, $40 \mathrm{mmol} / \mathrm{L}$ sodium chloride, $2 \mathrm{mmol} / \mathrm{L}$ EDTA, 1.5 $\mathrm{mmol} / \mathrm{L}$ sodium orthovanadate, $50 \mathrm{mmol} / \mathrm{L}$ sodium fluoride, $10 \mathrm{mmol} / \mathrm{L}$ sodium pyrophosphate, $10 \mathrm{mmol} / \mathrm{L}$ sodium 2-glycerophosphate at pH 7.4) containing Halt protease/phosphatase inhibitor (Thermo Scientific, Wilmington, DE).

\section{Total EAA and Insulin Interaction on mTORC1 Activity}

In an initial $3 \times 5$ factorial experiment $(\mathrm{n}=3)$, MAC$\mathrm{T}$ were incubated in experimental media containing 1 of 3 concentrations of insulin $(1,10$, or $100 \mathrm{nmol} / \mathrm{L})$ and 1 of 5 levels of EAA as in Table $1(10,50,100,1,000$, or $3,000 \mu \mathrm{mol} / \mathrm{L})$. Individual EAA concentrations were determined with the same criteria as NEAA, based on published plasma total EAA concentration and the profile of milk proteins (Table 1). The $1,000 \mu \mathrm{mol} / \mathrm{L}$ total EAA concentration represents approximately $100 \%$ of the reference plasma level for each AA.

\section{Individual EAA and Insulin Interactions on mTORC1 Activity}

The effects of individual EAA at increasing concentrations were then tested. The AA Arg, Ile, Leu, and Met were individually tested in separate $4 \times 3$ factorial experiments $(\mathrm{n}=4)$ at $0,1,10$, or $100 \mathrm{nmol} / \mathrm{L}$ insulin $($ Arg at $0,25,50$, or $150 \mu \mathrm{mol} / \mathrm{L}$; Ile at $0,65,130$, or $390 \mu \mathrm{mol} / \mathrm{L}$; Leu at $0,10,100$, or $450 \mu \mathrm{mol} / \mathrm{L}$; Met at $0,25,50$, or $150 \mu \mathrm{mol} / \mathrm{L})$. Essential AA expected to have no or minimal effects on mTORC1 (His 0,50 , or $150 \mu \mathrm{mol} / \mathrm{L}$; Lys 0,160 , or $480 \mu \mathrm{mol} / \mathrm{L}$; Phe 0 , 90, or $270 \mu \mathrm{mol} / \mathrm{L}$; Thr 0, 100, or $300 \mu \mathrm{mol} / \mathrm{L}$; Trp 0, 20, or $60 \mu \mathrm{mol} / \mathrm{L}$; Val 0, 160, or $480 \mu \mathrm{mol} / \mathrm{L})$ were only tested at the maximum insulin concentration $(100 \mathrm{nmol} / \mathrm{L}$, $\mathrm{n}=4)$. To ensure sufficient power for the expected smaller effect sizes with individual rather than total EAA, an $\mathrm{n}$ of 4 rather than 3 was used for all individual AA experiments.

\section{Grouped EAA on mTORC1 Activity}

Following the individual AA experiments, the EAA were then grouped by their effects on mTORC1 activity and tested in a $2 \times 2$ factorial design arrangement $(\mathrm{n}$ $=4)$. MAC-T were incubated in media at $100 \mathrm{nmol} / \mathrm{L}$ insulin and containing either zero EAA (OEAA); the combination of $50 \mu \mathrm{mol} / \mathrm{L}$ His, $160 \mu \mathrm{mol} / \mathrm{L}$ Lys, 90 $\mu \mathrm{mol} / \mathrm{L}$ Phe, $50 \mu \mathrm{mol} / \mathrm{L}$ Trp, and $160 \mu \mathrm{mol} / \mathrm{L}$ Val (nonsignificant for mTORC1 stimulation, NTORAA); the combination of $50 \mu \mathrm{mol} / \mathrm{L} \mathrm{Arg,} 130 \mu \mathrm{mol} / \mathrm{L}$ Ile, $200 \mu \mathrm{mol} / \mathrm{L} \mathrm{Leu,} 50 \mu \mathrm{mol} / \mathrm{L} \mathrm{Met}$, and $100 \mu \mathrm{mol} / \mathrm{L}$ Thr (significant for mTORC1 stimulation, TOR-AA); or containing all 10 EAA at their specified concentrations in each group (TEAA). As with individual AA experiments, an $\mathrm{n}$ of 4 was used here to ensure sufficient power for expected smaller effect size.

\section{Protein and Phosphorylation Levels}

Concentrations of total protein in each sample were determined with bicinchoninic acid assay (BioVision, Milpitas, CA) following manufacturer's instructions. Denatured proteins $(20 \mu \mathrm{g})$ were electrophoretically separated in $8 \%$ and $16 \%$ Novex Tris-glycine mini gels (Thermo Fisher Scientific, Waltham, MA) and wet-transferred onto nitrocellulose membranes. Membranes were blocked with Odyssey blocking buffer (LI-COR Biosciences, Lincoln, NE) diluted 1:1 with tris-buffered saline for $1 \mathrm{~h}$, then incubated overnight at $4^{\circ} \mathrm{C}$ with primary antibodies for the $\beta$-actin (Cell Signaling Technology, Danvers, MA) or heat shock protein 90 (HSP90, item no. H90-10, Developmental 
Studies Hybridoma Bank, Iowa City, IA) as loading control, and total and phosphorylated forms of eukaryotic translation initiation factor 4E-binding protein 1 (4E-BP1, Ser65, sc-81149, Santa Cruz Biotechnology, Dallas, TX); ribosomal protein S6 kinase p70 (S6K1, Thr389, S6K1, MAB8962, R\&D Systems, Minneapolis, MN); Akt (Ser473, 2920,Cell Signaling Technology), ribosomal protein S6 (S6, Ser240/244, 2317, Cell Signaling Technology), phosphorylated 4E-BP1 (Ser65, 9451, Cell Signaling Technology); phosphorylated S6K1 (Thr389, 9234, Cell Signaling Technology); phosphorylated Akt (Ser473, 4060, Cell Signaling Technology); and phosphorylated S6 (Ser240/244, 5364, Cell Signaling Technology) in Odyssey blocking buffer diluted 1:1 with tris-buffered saline and $0.05 \%$ polysorbate 20 . All primary antibodies were diluted at 1:1,000, except for antibodies for 4E-BP1 and S6K1, which were diluted at $2: 1,000$.

Primary antibody-bound membranes were incubated with relevant fluorescent (0.5:10,000 dilution; goat anti-mouse IgG IRDye 680 RD 68070, goat anti-rabbit IgG IRDye 800CW 32211, LI-COR Biosciences) or chemiluminescent (5:10,000 dilution; horseradish peroxidase-linked goat anti-rabbit IgG 7074, horseradish peroxidase-linked goat anti-mouse 7076, Cell Signaling Technology) secondary antibodies for $1 \mathrm{~h}$ at room temperature before imaging on an Odyssey Fc imaging system (LI-COR Biosciences). Band intensities were quantified with ImageStudio software (LI-COR Biosciences). Phosphorylation of target proteins was calculated as the phosphorylate-to-total protein $(\mathbf{P} / \mathbf{T})$ ratio of each target or phosphorylated-to-control protein $(\mathbf{P} / \mathbf{C}$, either $\beta$-actin or HSP90) ratio for each target.

\section{Statistical Analyses}

The main effects of total or individual EAA, insulin, and the interaction between these factors for each signaling protein were analyzed as the $\mathrm{P} / \mathrm{T}, \mathrm{P} / \mathrm{C}$, or total-to-loading-control ratios for each target using the lm function in RStudio (R-3.5.2; Boston, MA). Both linear and quadratic parameters were estimated for the total or individual EAA in each experiment. Model selection for total and individual EAA experiments was performed by backward elimination, with terms at $P>$ 0.10 removed, first to last, in the order: quadratic interaction, quadratic main effects, and single interaction. The initial statistical model before any elimination was defined as

$$
\begin{gathered}
Y_{i}=\beta_{0}+\beta_{1} x_{i}+\beta_{2} w_{i}+\beta_{3} w_{i}^{2}+\beta_{4}\left(x_{i} \times w_{i}\right) \\
+\beta_{5}\left(x_{i} \times w_{i}^{2}\right)+e_{i},
\end{gathered}
$$

where $Y_{i}=\mathrm{P} / \mathrm{T}, \mathrm{P} / \mathrm{C}$, or total-to-loading-control ratio; $x_{i}=$ concentration of insulin; $w_{i}=$ concentration of total or individual EAA; $\beta_{0}=$ intercept estimate; $\beta_{1}=$ linear parameter estimate for insulin; $\beta_{2}, \beta_{3}=$ respectively linear and quadratic parameter estimates for total or individual EAA; $\beta_{4}=$ parameter estimate for the linear interaction between insulin and $\mathrm{AA} ; \beta_{5}=$ parameter estimate for the interaction between insulin and quadratic $\mathrm{AA}$; and $e_{i}=$ random error. Normality of residuals was assessed visually and with the Shapiro-Wilk test. Outliers were identified and removed based on falling outside $1.5 \times$ the interquartile range. For grouped EAA, the treatment effect on mTORC1 pathway target phosphorylation by $\mathrm{P} / \mathrm{T}$ ratio were determined with the aov function in Rstudio, followed by multiple comparisons with Tukey's honest significant difference. Significance was declared at $P \leq 0.05$ and tendency at $0.05<P \leq 0.10$.

\section{RESULTS}

\section{Total EAA and Insulin Interaction on mTORC1 Activity}

Insulin significantly increased the phosphorylation of its canonical downstream effector Akt $(P<0.001$; Table 2 and Figure 1A). Although Akt abundance did not change $(P>0.10)$, when phosphorylated Akt was normalized to $\beta$-actin, EAA tended to interact with insulin $(P=0.07)$, dampening its effect. Essential AA quadratically increased phosphorylation of the mTORC1 substrate S6K1 in an insulin-dependent fashion when normalized as $\mathrm{P} / \mathrm{T}(P=0.008$, Figure $1 \mathrm{~B})$ and linearly when normalized as $\mathrm{P} / \mathrm{C}(P=0.02$, Figure 1C), while S6K1 abundance tended to be decreased by EAA in an insulin-dependent fashion $(P=0.09)$. Insulin also increased phosphorylation of the mTORC1 substrate and mRNA translation initiation inhibitor 4E-BP1 $(P=0.04)$, whereas EAA stimulated 4E-BP1 phosphorylation in a quadratic and insulin-dependent fashion when 4E-BP1 phosphorylation was normalized as $\mathrm{P} / \mathrm{C}(P=0.008)$. However, $4 \mathrm{E}-\mathrm{BP} 1$ protein abundance was not significantly affected by any factor $(P$ $>0.20)$. Essential AA and insulin linearly and independently increased the phosphorylation of the S6K1 substrate S6 $(P \leq 0.001)$ without affecting total S6 protein abundance $(P>0.90)$.

\section{Individual EAA and Insulin Interactions on mTORC1 Activity}

Insulin linearly increased phosphorylation of Akt in every experiment with individual AA $(P<0.001$, Table 3 and Figure 2). Among the 4 EAA studied, 
Pszczolkowski et al.: INSULIN POTENTIATES ESSENTIAL AMINO ACID EFFECTS ON MTORC1

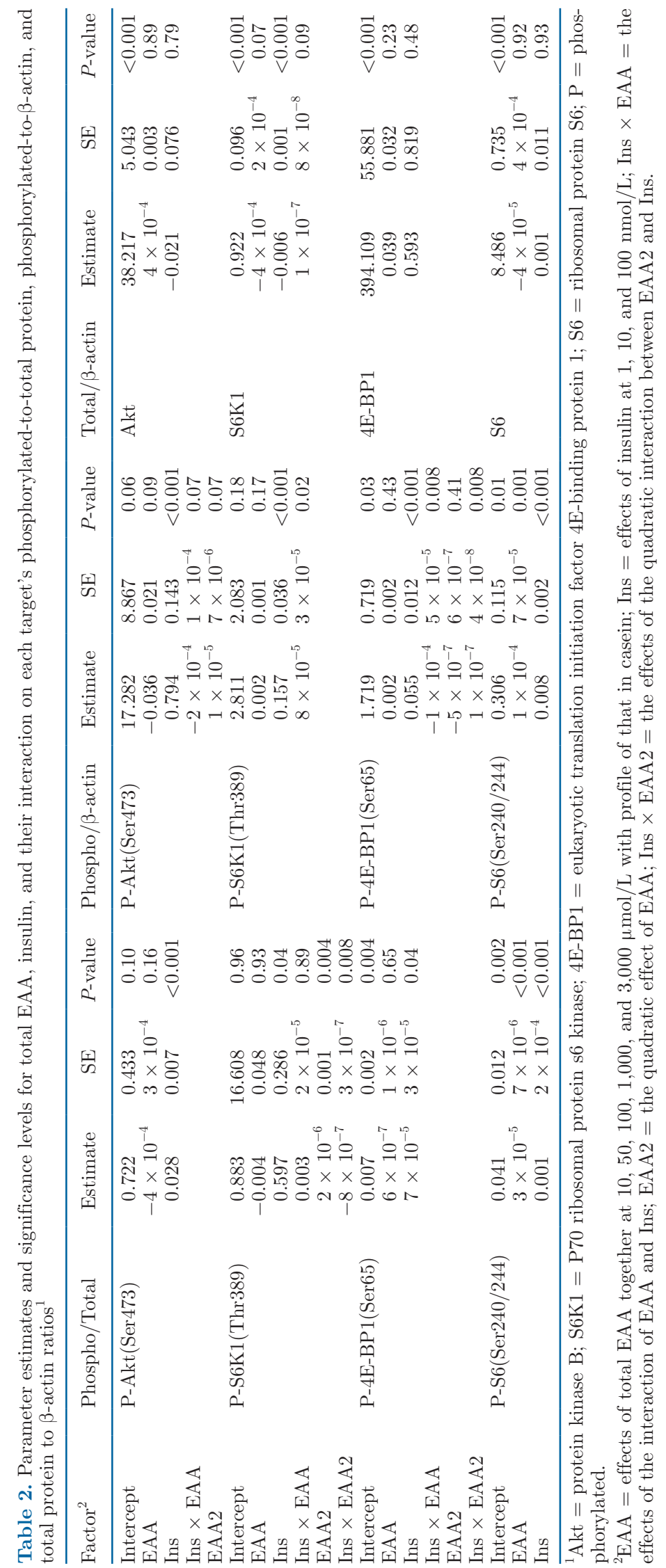



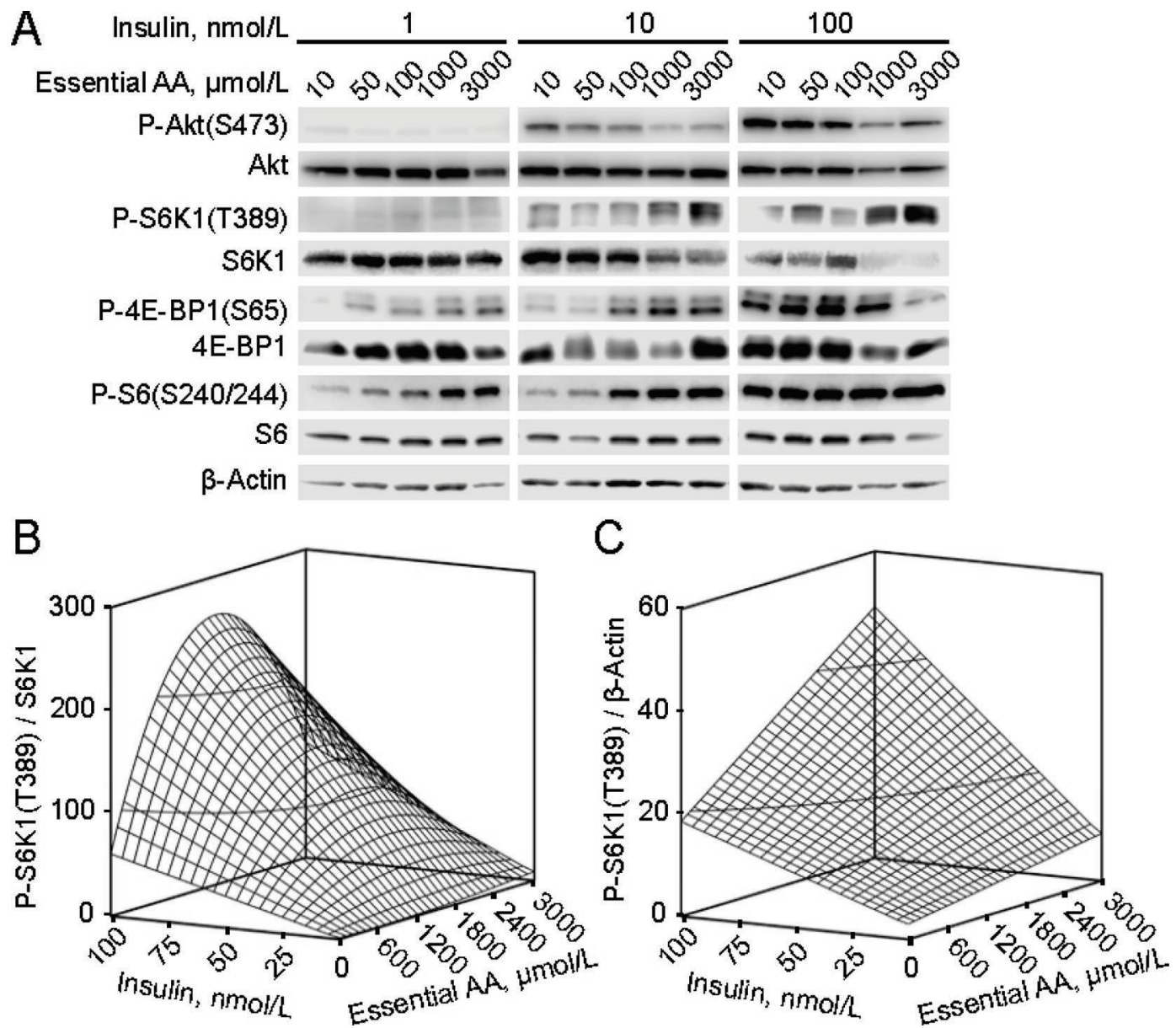

Figure 1. Phosphorylation of mechanistic target of rapamycin complex 1 (mTORC1) pathway proteins in MAC-T in response to insulin and total EAA. (A) Western blot image scans for phosphorylated (P) and total forms of Akt, P70 ribosomal protein s6 kinase (S6K1), eukaryotic translation initiation factor 4E-binding protein (4E-BP1), ribosomal protein S6 (S6), and $\beta$-actin as loading control. (B) Predicted insulin and total EAA interactive effect on S6K1(T389) phosphorylated-to-total ratio. (C) Predicted insulin and total EAA interactive effect on S6K1(T389) phosphorylated-to- $\beta$-actin ratio.

only Leu tended to decrease the effect of insulin on Akt phosphorylation $(P=0.10)$, but the effect was not significant as for the total EAA. Similar to total EAA, Leu quadratically increased S6K1 phosphorylation in an insulin-dependent fashion, with a marked decrease in phosphorylation at supraphysiologically high Leu and insulin $(P=0.003$, Figure $2 \mathrm{~A})$, and tended to do the same for the phosphorylation of S6 $(P=0.10)$. Leucine did not affect $4 \mathrm{E}-\mathrm{BP} 1$ phosphorylation, which was linearly increased by insulin $(P<0.001)$. Methionine linearly increased phosphorylation of S6K1 and 4E-BP1 in an insulin-dependent fashion $(P<0.001$, Figure $2 \mathrm{~B})$. Methionine independently increased S6 phosphorylation $(P<0.001)$, which was also increased by insulin $(P=0.04)$. Isoleucine increased S6K1 phosphorylation in a quadratic and insulin-dependent fashion $(P=0.01$, Figure 2C). Isoleucine only tended to increase 4E-BP1 $(P=0.10)$ and $\mathrm{S} 6(P=0.09)$ phosphorylation in an insulin-dependent fashion. Arginine linearly increased phosphorylation of S6K1 $(P<0.001$, Figure 2D) and 4E-BP1 $(P=0.001)$, while only tending to increase phosphorylation of S6 $(P=0.10)$, with all 3 effects being insulin-dependent.

Other EAA were tested for an effect on S6K1 as P/C under the highest insulin concentration, $100 \mathrm{nmol} / \mathrm{L}$. Threonine linearly increased S6K1 phosphorylation $(P$ $=0.045)$. Histine, Lys, Trp, and Val had no significant effect $(P>0.10$, Figure 3$)$, and Phe quadratically decreased S6K1 phosphorylation by $\mathrm{P} / \mathrm{C}(P=0.01)$.

\section{Grouped EAA on mTORC1 Activity}

There was a significant overall treatment effect on phosphorylation by $\mathrm{P} / \mathrm{T}$ of S6K1, 4E-BP1, S6, and Akt $(P \leq 0.001$, data not shown) with insulin held at 100 nmol/L. Grouping the 5 NTOR-AA at plasma concen- 
Pszczolkowski et al.: INSULIN POTENTIATES ESSENTIAL AMINO ACID EFFECTS ON MTORC1

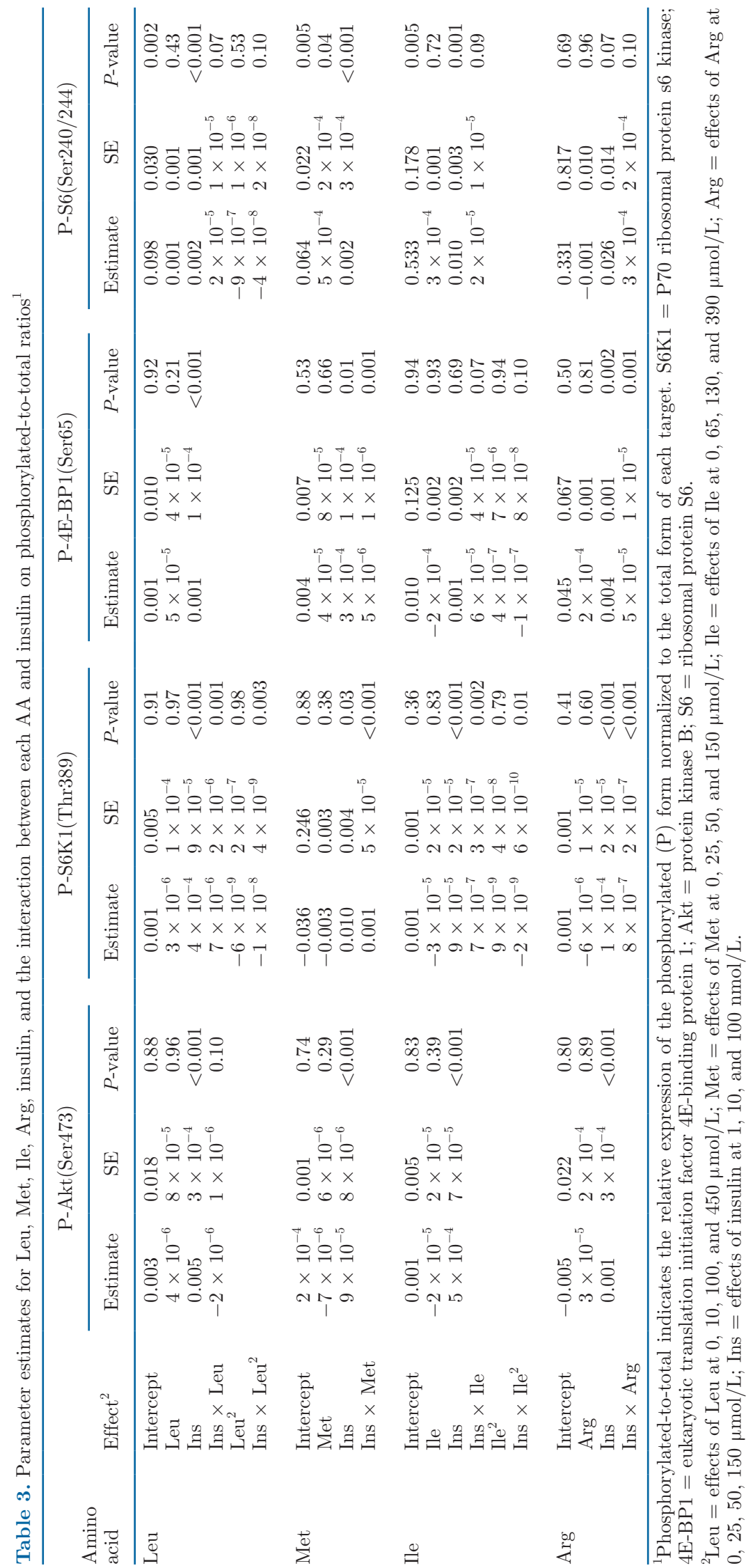



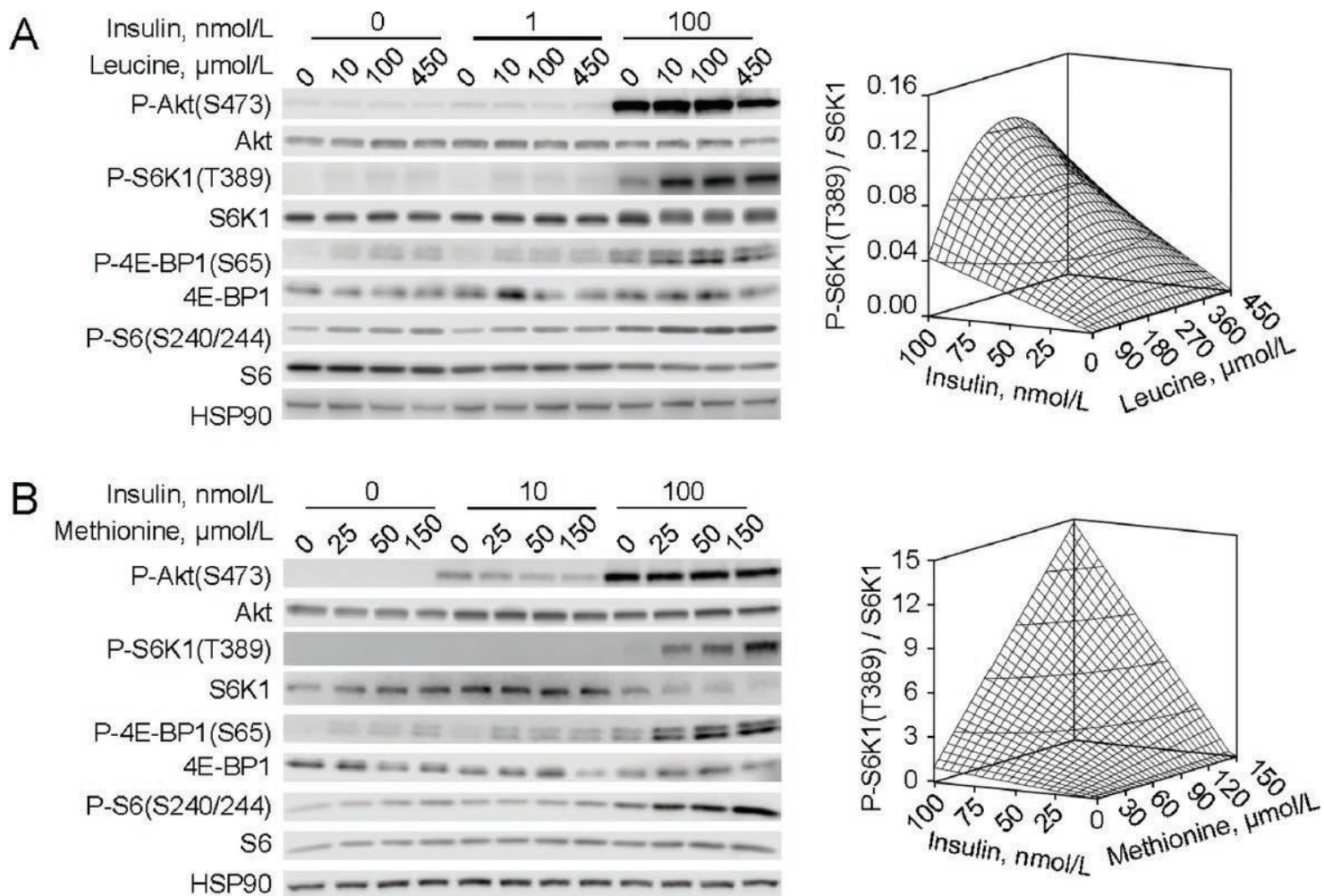

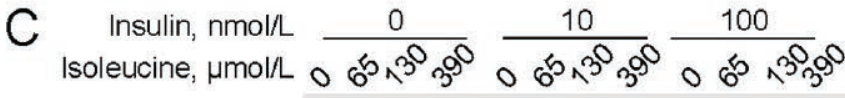 P-Akt(S473)
Akt $--\div-\div-\div-$ P-S6K1(T389) $-\infty-$
S6K1 *- - - - - - - -
$\mathrm{P}-4 \mathrm{E}-\mathrm{BP} 1(\mathrm{~S} 65) \div-\cdots-\cdots$ 4E-BP1 - - - - - - - -
$\mathrm{P}-\mathrm{S6}(\mathrm{S} 240 / 244) \div-\ldots-\cdots-\cdots$
S6 - - - - - - - - HSP9O $-\cdots-\cdots-\cdots$

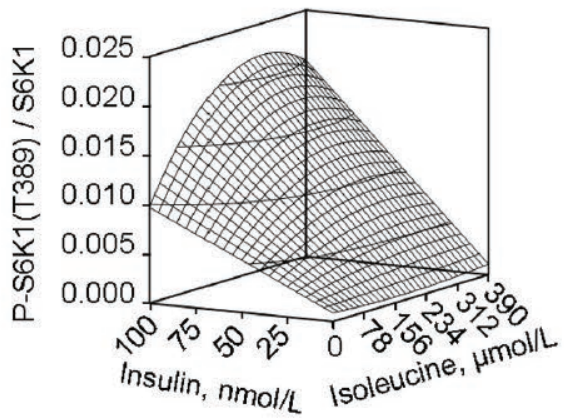

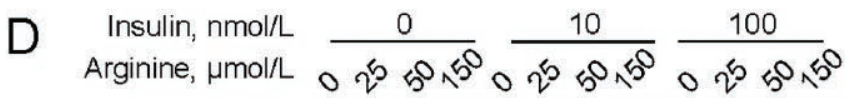
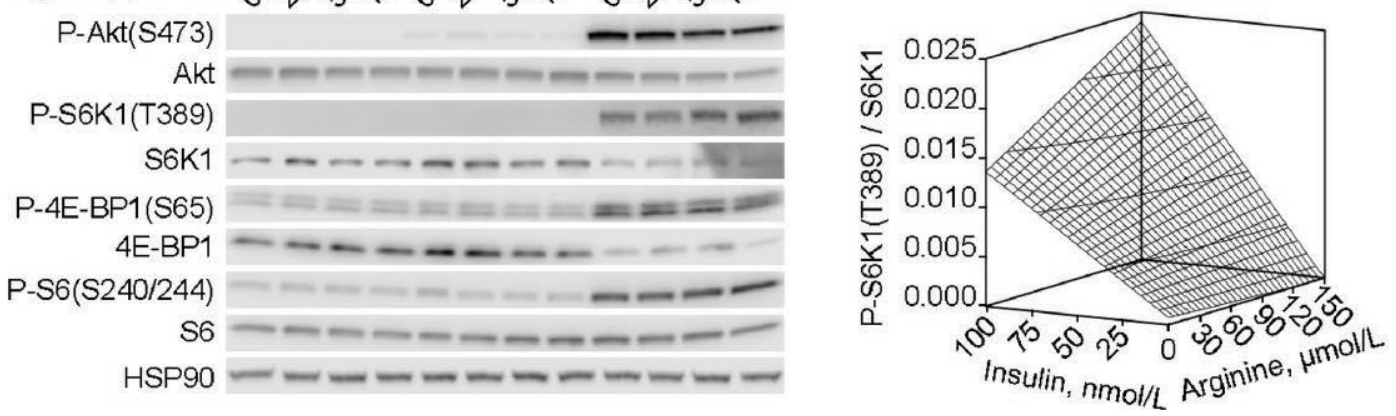

Figure 2. Phosphorylation of mechanistic target of rapamycin complex 1 (mTORC1) pathway proteins in MAC-T in response to insulin and either (A) Leu, (B) Met, (C) Ile, or (D) Arg. Western blot image scans for phosphorylated (P) and total forms of Akt, P70 ribosomal protein s6 kinase (S6K1), eukaryotic translation initiation factor 4E-binding protein (4E-BP1), ribosomal protein S6 (S6), and heat shock protein 90 (HSP90) as loading control. Predicted insulin and individual EAA interactive effect on S6K1(T389) phosphorylated-to-total ratios for (A) Leu, (B) Met, (C) Ile, or (D) Arg. 
trations (Table 1) had no effect on S6K1 phosphorylation relative to 0EAA, either when normalized to total S6K1 or the control protein HSP90 $(P>0.05$, Figure $4 \mathrm{~A})$. On the other hand, the TOR-AA group, also at plasma concentrations, increased $\mathrm{S} 6 \mathrm{~K} 1 \mathrm{P} / \mathrm{T}$ by 6 -fold compared with both OEAA and NTOR-AA alone. The TEAA treatment resulted in a similarly large increase in S6K1 $\mathrm{P} / \mathrm{T}$ compared with 0EAA and NTOR-AA alone, confirming that NTOR-AA have no effect on mTORC1 activity with respect to S6K1 phosphoryla- tion. When normalized as $\mathrm{P} / \mathrm{C}$, the effect of TEAA on S6K1 phosphorylation was less than that of TOR-AA $(P<0.05)$, but there was no significant effect of any treatment on total S6K1 abundance $(P=0.12)$.

Interestingly, total 4E-BP1 abundance was almost eliminated by both TOR-AA-containing groups $(P<$ 0.05 , Figure $4 \mathrm{~B})$, such that when normalized as $\mathrm{P} / \mathrm{T}$ 4E-BP1 phosphorylation was significantly affected by neither NTOR-AA nor TOR-AA, but was increased by TEAA $(P<0.05)$. When normalized as $\mathrm{P} / \mathrm{C}$, NTOR-
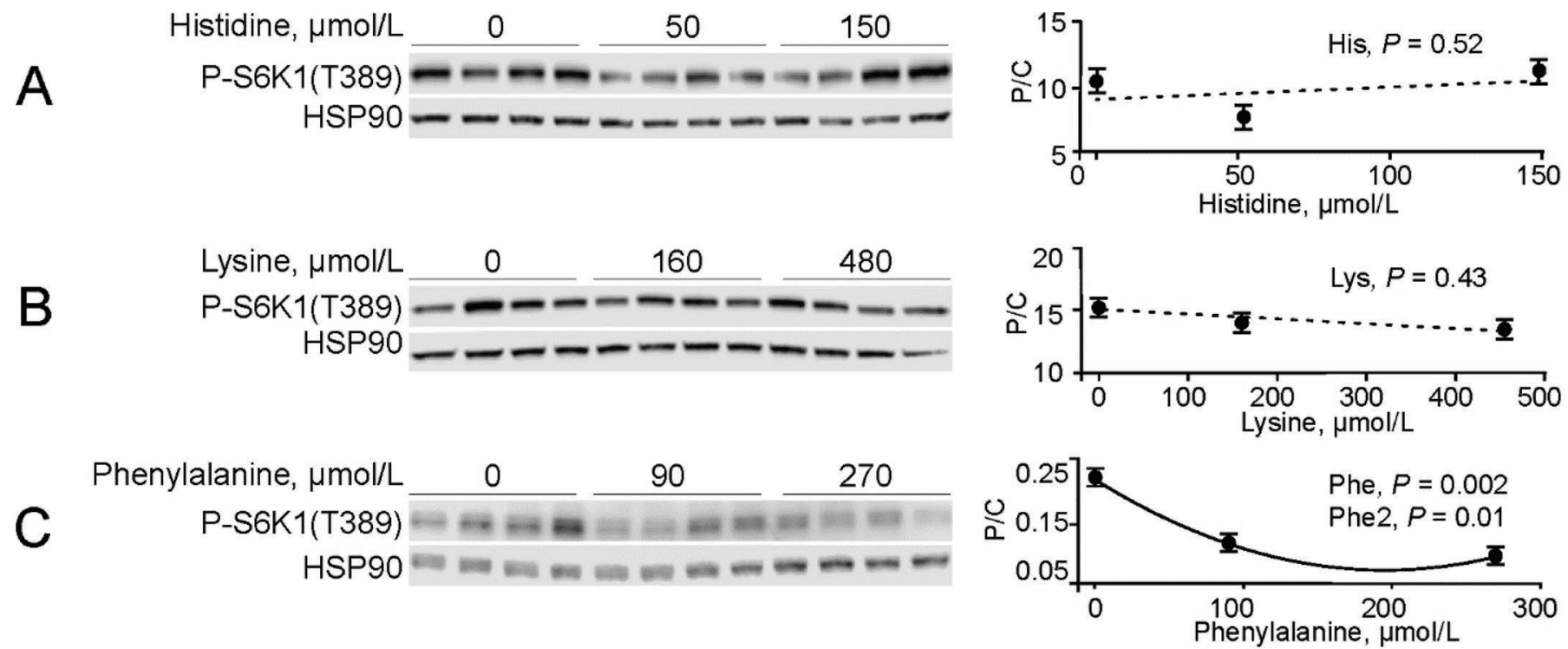

D

Threonine, $\mu \mathrm{mol} / \mathrm{L}$ $100 \quad 300$ P-S6K1(T389)
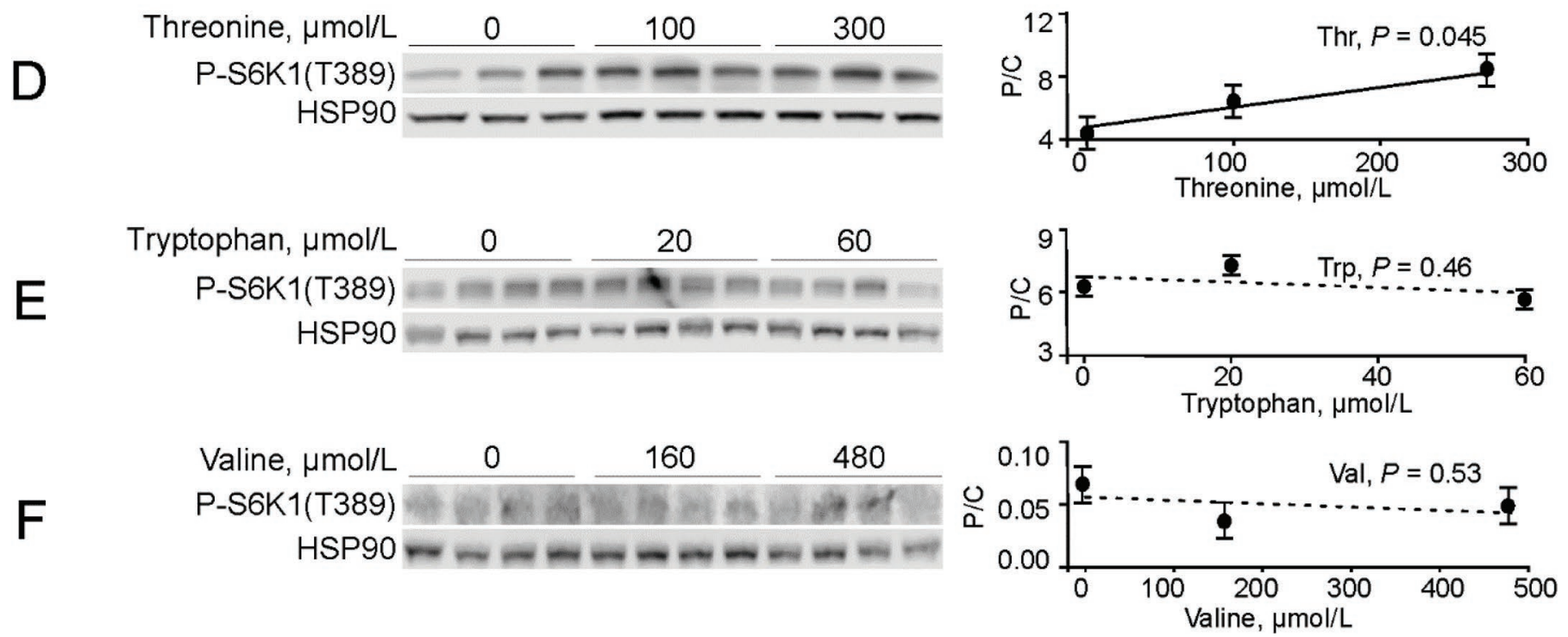

Figure 3. Phosphorylation of mechanistic target of rapamycin complex 1 (mTORC1) pathway proteins in MAC-T in response to either (A) His, (B) Lys, (C) Phe, (D) Thr, (E) Trp, or (F) Val with insulin held constant at $100 \mathrm{nmol} / \mathrm{L}$. Western blot image scans for phosphorylated (P) forms of P70 ribosomal protein S6 kinase (S6K1) and heat shock protein 90 (HSP90) as loading control. Predicted linear or quadratic individual EAA effect on S6K1(T389) phosphorylated-to-HSP90 (P/C) ratios for His, Lys, Phe, Thr, Trp, or Val. Solid lines represent marginal-tosignificant $(P \leq 0.05)$ effect of the individual EAA in the model, and dotted lines represent no significant effect of individual EAA $(P>0.05)$. $P$-values correspond linear effect of individual AA; in (C) Phe2 corresponds to the quadratic effect of Phe. Solid dots are LSM for treatments and error bars are SE. 
A
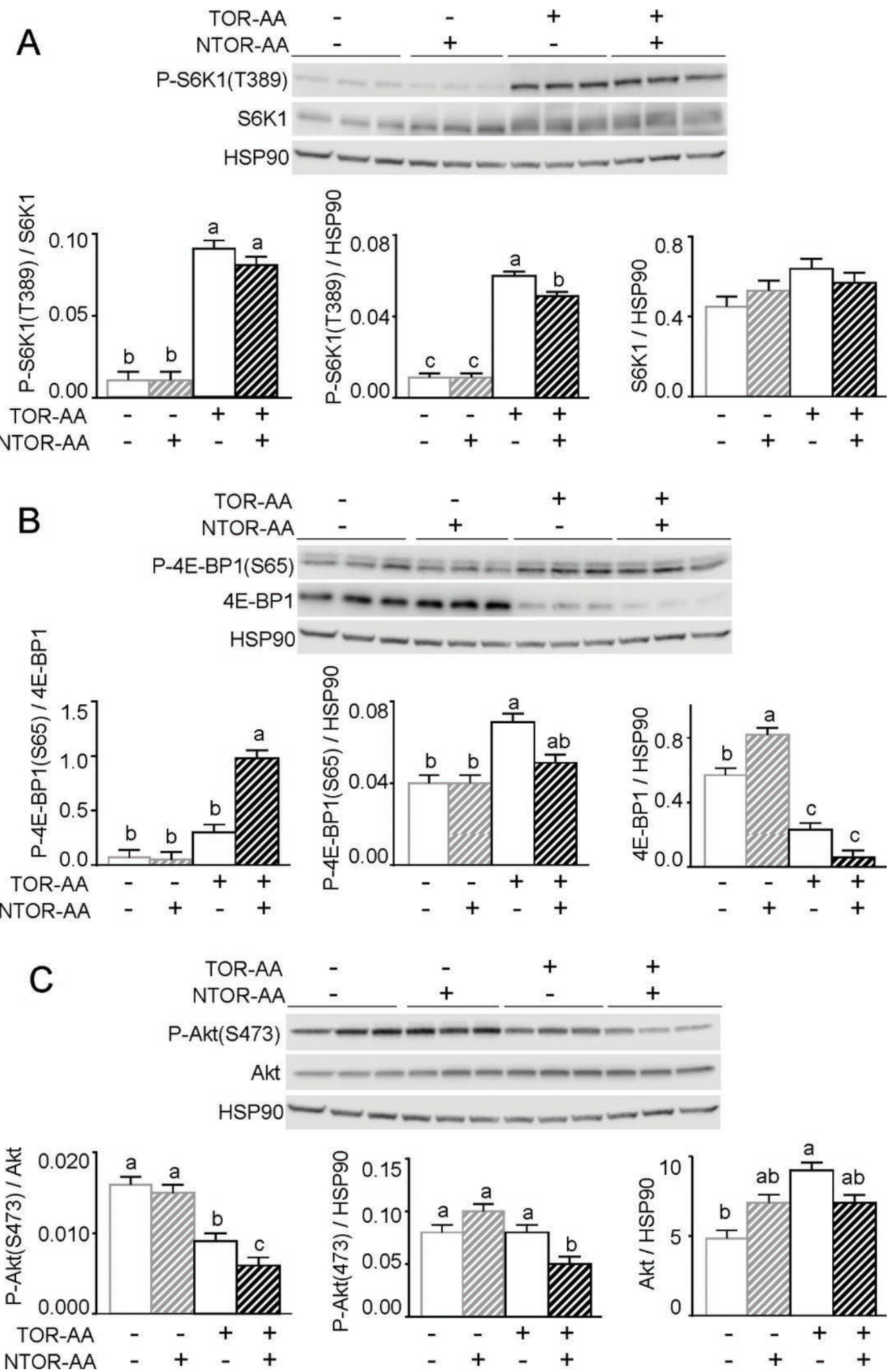

Figure 4. Phosphorylation of mTORC1 pathway proteins in MAC-T in response to TOR-AA (Leu, Met, Ile, Arg, and Thr), NTOR-AA (His, Lys, Phe, Trp, and Val), or both, with insulin held constant at $100 \mathrm{nmol} / \mathrm{L}$. Western blot image scans for total and phosphorylated (P) forms of mTORC1 pathway proteins: (A) P70 ribosomal protein s6 kinase (S6K1), (B) eukaryotic translation initiation factor 4E-binding protein (4EBP1), and (C) Akt; all (A-C) with heat shock protein 90 (HSP90) as loading control. Phosphorylated-to-total, phosphorylated-to-HSP90, and total-to-HSP90 ratios for (A) S6K1, (B) 4E-BP1, and (C) Akt in response to TOR-AA, NTOR-AA, or both displayed as bar graphs. Data are presented as LSM and error bars are SE. Different letters denote significance difference $(P \leq 0.05)$ by Tukey's test. 
AA had no effect on 4E-BP1 phosphorylation. The TOR-AA group significantly increased 4E-BP1 phosphorylation as $\mathrm{P} / \mathrm{C}(P<0.05)$, but to a lesser degree than observed for S6K1 (2-fold vs. 6-fold), whereas TEAA had an intermediate effect.

The Akt phosphorylation was decreased by both TOR-AA-containing treatments when normalized as $\mathrm{P} / \mathrm{T}(P<0.05$, Figure $4 \mathrm{C})$, with TOR-AA being intermediate from TEAA. When normalized to HSP90 as $\mathrm{P} / \mathrm{C}$, the effect only remained significant for the TEAA group. Total Akt abundance did respond to an overall treatment effect $(P=0.003)$, but without the TORAA-versus-NTOR-AA pattern seen with $4 \mathrm{E}-\mathrm{BP} 1$ and S6.

\section{DISCUSSION}

As a kinase complex, mTORC1 is defined by the phosphorylation of its substrates, of which 4E-BP1 and S6K1 are the 2 most directly involved in protein translation (Jefferies, 1997; Gingras et al., 2001). The ribosomal protein $\mathrm{S} 6$ is itself phosphorylated by $\mathrm{S} 6 \mathrm{~K} 1$ at Ser240/244 when S6K1 is activated by mTORC1 (Bandi et al., 1993), and although its specific role in translation is not yet resolved (Ruvinsky and Meyuhas, 2006), phosphorylation of this $40 \mathrm{~S}$ ribosomal protein is a useful if indirect marker of mTORC1 activity (Chowdhury and Köhler, 2015).

Activation of mTORC1 is mainly controlled by nutritional signals in a bimodal action. Amino acids determine the localization of mTORC1 to the lysosomal membrane by controlling the activity of the Ragulator complex (Sancak et al., 2010). Once mTORC1 is docked at the lysosome, insulin controls mTORC1 activation via the small GTPase Rheb (Manning and Cantley, 2003). Upstream of mTORC1, Akt is the canonical intracellular mediator of insulin signaling. Full Akt activation requires phosphorylation of its Ser 473 residue by the mechanistic target of rapamycin complex 2 (mTORC2), in an insulin-dependent manner (Sarbassov, 2005). Once activated, Akt phosphorylates tuberous sclerosis complex 2 (TSC2). TSC2 is a member of the TSC complex, along with TSC1 and Tre2Bub2-Cdc16 1 domain family, member 7 (TBC1D7; Dibble et al., 2012). This phosphorylation releases the inhibitory effect of the TSC complex on the mTORC1 activator Rheb (Manning and Cantley, 2003). Active Akt also stimulates substrate (e.g., 4E-BP1) binding to mTORC1 by phosphorylating the substrate-binding competitor PRAS40 (Wang et al., 2007; Nascimento et al., 2010). On the other hand, Akt signaling is itself attenuated by a negative feedback loop initiated by active mTORC1 (Harrington et al., 2005). With these roles for the up- and downstream effectors of the mTORC1 pathway in mind, we decided to test the molecular model of mTORC1 regulation by insulin and amino acids in MAC-T cells.

\section{Insulin Enhances the Effect of EAA on mTORC1 Activity}

Previous work in MAC-T cells and bovine mammary tissue slices suggested that EAA can stimulate mTORC1 independently of insulin (Appuhamy et al., 2011a), challenging the above model. Using a more comprehensive experimental design, with 3 levels of insulin and 5 levels of EAA, we observed that in line with the molecular model of mTORC1 regulation, insulin potentiates the stimulatory effect of EAA on mTORC1 substrates phosphorylation in MAC-T. Although the interaction between EAA and insulin was removed from the model with S6(Ser240/244) phosphorylation, $\mathrm{S} 6$ is downstream of direct mTORC1 action (Bandi et al., 1993), and so dynamics here are likely not directly comparable with S6K1 and 4E-BP1. Our results were further supported by a trend for an interaction on Akt phosphorylation, in which EAA inhibited insulin stimulation of Akt phosphorylation. Although we report no direct evidence that this decrease in Akt (Ser473) phosphorylation is mediated by a negative feedback loop from mTORC1, it does indicate that EAA may promote insulin resistance in MAC-T cells.

Concerning the surprising decrease in total S6K expression with high levels of insulin and to an extent total EAA, evidence in other cell types indicate that phosphorylation of S6K1 (Thr389) by mTORC1 is likely stabilizing (Zhang et al., 2013) rather than degradation-inducing, as is suggested in our results. Although degradation of signaling proteins on the order of hours is not unheard of (Kimball et al., 2007), generally such processes occur over days or more (Spector, 1974), so potentially the decrease in apparent S6K1 protein level was a byproduct of the Western blot primary antibody failing to bind to the target when hyperphosphorylated, either at Thr389 alone or at multiple residues. Even without the potentially artificial increase in S6K1 P/T brought about by diminished total S6K, the increase in S6K1 phosphorylation by insulin and EAA was confirmed by normalization to $\beta$-actin as $\mathrm{P} / \mathrm{C}$.

Once we determined that indeed insulin is required for EAA activation of mTORC1, we wanted to confirm if this same effect was true for individual EAA known to stimulate mTORC1 activity. The AA Leu, Arg, and more recently Met have their mechanisms for activation of mTORC1 largely elucidated (Chantranupong et al., 2016; Wolfson et al., 2016; Gu et al., 2017), and these 3 AA have all shown effects on mTORC1 activity in mammary epithelial cells (Appuhamy et al., 
2012; Ma et al., 2018; Zhou et al., 2018). In addition, Ile is a strong activator of mTORC1 in mammary tissue (Appuhamy et al., 2012). Overall, similar to total EAA, individual EAA effect on mTORC1 activity as determined by S6K1 phosphorylation was dependent on insulin.

A somewhat unexpected outcome with both total and individual EAA was a decrease in S6K1 phosphorylation at high levels of total EAA and the individual Leu and Ile, as evidenced by the quadratic surface responses and subtly apparent in the immunoblots themselves for the high insulin treatment. Potentially, this decline in effect at high AA levels is due to many EAA, particularly Leu and Ile, being stimulatory to mTORC1 while sharing the L-type AA transport system (Wang and Holst, 2015), such that excessive concentration of a given AA may prevent transport and subsequent signaling capability of another. Antagonistic effects such as this have previously been shown in bovine mammary tissue slices, with high concentrations of one EAA dropping the signaling response to another (Arriola Apelo et al., 2014b).

The relationship these EAA have with insulin in MAC-T with respect to mTORC1 kinase activity is a key takeaway from these results, as it provides a cellular and molecular basis for the production response to EAA observed in lactating animals. With regard to total EAA, multiple groups have reported a response in milk protein production to infused or supplemented EAA only when these AA were accompanied by insulin infusion (Mackle et al., 2000; Bequette et al., 2001; Dunshea et al., 2005) or abomasal infusion of starch, which is an insulinemic energy source (Rius et al., 2010).

\section{Not All EAA are Stimulatory to mTORC1}

Given the evidence in regard to AA known to stimulate mTORC1, we chose to investigate whether AA not known to stimulate mTORC1 at physiological concentrations could indeed stimulate mTORC1 at a supraphysiological concentration of insulin in MAC-T cells. Lysine and to a lesser degree His are considered limiting AA in lactating dairy cows (Lapierre et al., 2008) and their supplementation individually or in combination is known to increase milk protein production (Schwab et al., 1976; Kim et al., 1999; Giallongo et al., 2016). Our work in MAC-T cells showed no relationship between either of these EAA and mTORC1 activity by S6K1 phosphorylation $(P>0.40)$ even at supraphysiological insulin levels, indicating that the mechanism by which these EAA regulate milk production is likely mTORC1 independent.
As one of the branched chain AA, Val is often grouped with Leu and Ile with regard to mTORC1 activation and as a dietary treatment (Appuhamy et al., 2011b; Doelman et al., 2015b), but evidence in a variety of tissues and species (Shannon et al., 2013; Reho et al., 2019) suggests that such a structure-based grouping does not necessarily correlate with the specific functions of these 3 AA. Previous work in MAC-T (Dong et al., 2018) and mammary tissue slices (Appuhamy et al., 2012) posits Val as having no effect on mTORC1 signaling or milk protein synthesis, which was supported by our findings showing that even at supraphysiological insulin, Val fails to stimulate S6K1 phosphorylation. For Phe, for which the role in mTORC1 signaling is more ambiguous (Appuhamy et al., 2012; Doelman et al., 2015a), we observed a significant curvilinear decrease in S6K1 phosphorylation as Phe was increased, showing that at the very least these AA do not promote mTORC1 activity in MAC-T.

Although we expected Thr alone to fail to stimulate mTORC1 activity, we instead observed a modest positive effect on S6K1 phosphorylation when insulin was set at a supraphysiological concentration. There is some evidence both in vivo and in vitro that Thr can regulate mammary mTORC1 activity, but as yet the results have not been particularly conclusive. In bovine mammary tissue slices, Thr positively regulated $\mathrm{P} / \mathrm{T}$ ratio for mTOR(Ser2448) but had an inhibitory effect on Ile stimulation of mTORC1's downstream effectors (Arriola Apelo et al., 2014a). As well in lactating mice, supplementation of a protein-restricted diet with $\mathrm{Thr}$ has been shown to increase the $\mathrm{P} / \mathrm{T}$ ratio for both mTOR(Ser2448) itself and 4E-BP1(Thr37/46) - not Ser65, as presented here - but without altering $\mathrm{P} / \mathrm{T}$ for S6K1(Thr389) or litter growth (Liu et al., 2017). More recently, working from the same conclusions on Thr signaling we have since drawn, Thr was included in a mixture of mTOR-stimulating AA also containing Leu, Met, and Ile for jugular infusion into lactating goats. However, although milk protein production was increased by this AA combination, mammary mTORC1 signaling was in fact decreased (Xu et al., 2019).

\section{A Select Group of EAA Are Responsible for Total EAA Stimulation of mTORC1 Activity}

Once we determined that individual NTOR-AA were unable to stimulate mTORC1 activity regardless of insulin priming, a remaining question was if those AA could have a combined effect, and if that effect was comparable to the effect of TOR-AA. In line with previous results, grouped NTOR-AA had no effect on mTORC1 activity as determined by phosphorylation 
of its canonical substrates. As expected, TOR-AA had a strong effect on mTORC1 activity, increasing S6K1 phosphorylation by 6 -fold compared with the control level. Fascinatingly, when combined all the EAA had similar effect to TOR-AA alone. Supporting the concept that signaling through mTORC1 by these select EAA is a deciding factor in the regulation of milk protein synthesis, a recent study (Zhao et al., 2019) in lactating cows fed a low-protein diet showed that rumen-protected Ile, Leu, Met, and Thr recovered milk protein yield from the level of a low-protein diet to that of a high-protein diet, along with increasing phosphorylation of mTORC1 pathway components to a similar degree. In line with this in vivo study, Yoder et al. (2019) indicated in primary bovine mammary epithelial cells that these same $4 \mathrm{EAA}$ are adequate to maintain stimulation of the mTORC1 pathway, regardless of the profiles of other EAA.

\section{CONCLUSIONS}

The results presented herein confirm our hypothesis that insulin is required in order for EAA to maximally stimulate mTORC1 kinase activity in MAC-T cells. Leucine, Ile, Met, Thr, and Arg are the only EAA to positively stimulate mTORC1 activity at physiological concentrations, whereas the remaining EAA His, Lys, Phe, Trp, and Val have no or even a negative effect. Additionally, the 5 mTORC1-stimulating EAA appear to be responsible for the entirety of the increase in mTORC1 activity when MAC-T are exposed to total EAA. This is despite Lys and His being considered first-limiting AA for milk production in dairy cattle, indicating that there are likely other important regulatory mechanisms in mammary cells that mediate the effect of these AA on milk production. Although the relationship between insulin and the mTORC1-stimulating EAA has been clearly defined in this in vitro model, animal and production response research is still required.

\section{ACKNOWLEDGMENTS}

This project was supported by the USDA National Institute of Food and Agriculture (Washington, DC), Hatch project 1014094. Jun Zhang received fellowship support from China Scholarship Council (CSC; Beijing). The monoclonal antibody H90-10, developed by Brian Freeman at the University of Illinois, UrbanaChampaign, was obtained from the Developmental Studies Hybridoma Bank, created by the Eunice Kennedy Shriver National Institute of Child Health and Human Development, of the NIH, and maintained at the Department of Biology, University of Iowa, Iowa
City, IA. We also thank Laura L. Hernandez (Department of Animal and Dairy Sciences, University of Wisconsin-Madison) for generously donating the MAC$\mathrm{T}$ stock used in these experiments. The authors have not stated any conflicts of interest.

\section{REFERENCES}

Appuhamy, J. A. D. R. N., A. L. Bell, W. A. D. Nayananjalie, J. Escobar, and M. D. Hanigan. 2011a. Essential amino acids regulate both initiation and elongation of mRNA translation independent of insulin in MAC-T cells and bovine mammary tissue slices. J. Nutr. 141:1209-1215. https://doi.org/10.3945/jn.110.136143.

Appuhamy, J. A. D. R. N., J. R. Knapp, O. Becvar, J. Escobar, and M. D. Hanigan. 2011b. Effects of jugular-infused lysine, methionine, and branched-chain amino acids on milk protein synthesis in high-producing dairy cows. J. Dairy Sci. 94:1952-1960. https://doi .org/10.3168/jds.2010-3442.

Appuhamy, J. A. D. R. N., N. A. Knoebel, W. A. D. Nayananjalie, J. Escobar, and M. D. Hanigan. 2012. Isoleucine and leucine independently regulate mTOR signaling and protein synthesis in MAC$\mathrm{T}$ cells and bovine mammary tissue slices. J. Nutr. 142:484-491. https://doi.org/10.3945/jn.111.152595.

Appuhamy, J. A. D. R. N., A. L. Bell, W. A. D. Nayananjalie, J. Escobar, and M. D. Hanigan. 2011c. Essential amino acids regulate both initiation and elongation of mRNA translation independent of insulin in MAC-T cells and bovine mammary tissue slices. J. Nutr. 141:1209-1215. https://doi.org/10.3945/jn.110.136143.

Arriola Apelo, S. I., L. M. Singer, X. Y. Lin, M. L. McGilliard, N. R. St-Pierre, and M. D. Hanigan. 2014a. Isoleucine, leucine, methionine, and threonine effects on mammalian target of rapamycin signaling in mammary tissue. J. Dairy Sci. 97:1047-1056. https:// doi.org/10.3168/jds.2013-7348.

Arriola Apelo, S. I., L. M. Singer, X. Y. Lin, M. L. McGilliard, N. R. St-Pierre, and M. D. Hanigan. 2014b. Isoleucine, leucine, methionine, and threonine effects on mammalian target of rapamycin signaling in mammary tissue. J. Dairy Sci. 97:1047-1056. https:// doi.org/10.3168/jds.2013-7348.

Bandi, H. R., S. Ferrari, J. Krieg, H. E. Meyer, and G. Thomas. 1993. Identification of $40 \mathrm{~S}$ ribosomal protein $\mathrm{S} 6$ phosphorylation sites in Swiss mouse 3T3 fibroblasts stimulated with serum. J. Biol. Chem. 268:4530-4533.

Bequette, B. J., C. E. Kyle, L. A. Crompton, V. Buchan, and M. D. Hanigan. 2001. Insulin regulates milk production and mammary gland and hind-leg amino acid fluxes and blood flow in lactating goats. J. Dairy Sci. 84:241-255. https://doi.org/10.3168/jds.S0022 -0302(01)74474-8.

Burgering, B. M. T., and P. J. Coffer. 1995. Protein kinase B (c-Akt) in phosphatidylinositol-3-OH kinase signal transduction. Nature 376:599-602.

Chantranupong, L., S. M. Scaria, R. A. Saxton, M. P. Gygi, K. Shen, G. A. Wyant, T. Wang, J. W. Harper, S. P. Gygi, and D. M. Sabatini. 2016. The CASTOR proteins are arginine sensors for the mTORC1 pathway. Cell 165:153-164. https://doi.org/10.1016/j .cell.2016.02.035.

Chew, B. P., J. R. Eisenman, and T. S. Tanaka. 1984. Arginine infusion stimulates prolactin, growth hormone, insulin, and subsequent lactation in pregnant dairy cows. J. Dairy Sci. 67:2507-2518. https://doi.org/10.3168/jds.S0022-0302(84)81607-0.

Chowdhury, T., and J. R. Köhler. 2015. Ribosomal protein S6 phosphorylation is controlled by TOR and modulated by PKA in Candida albicans. Mol. Microbiol. 98:384-402. https://doi.org/10 $.1111 / \mathrm{mmi} .13130$.

Colaço, A., and M. Jäättelä. 2017. Ragulator-A multifaceted regulator of lysosomal signaling and trafficking. J. Cell Biol. 216:38953898. https://doi.org/10.1083/jcb.201710039.

Debras, E., J. Grizard, E. Aina, S. Tesseraud, C. Champredon, and M. Arnal. 1989. Insulin sensitivity and responsiveness during lactation and dry period in goats. Am. J. Physiol. Endocrinol. Metab. 
256:E295-E302.

https://doi.org/10.1152/ajpendo.1989.256.2 .E295.

Dibble, C. C., W. Elis, S. Menon, W. Qin, J. Klekota, J. M. Asara, P. M. Finan, D. J. Kwiatkowski, L. O. Murphy, and B. D. Manning. 2012. TBC1D7 is a third subunit of the TSC1-TSC2 complex upstream of mTORC1. Mol. Cell 47:535-546. https://doi.org/10 .1016/j.molcel.2012.06.009.

Doelman, J., R. V. Curtis, M. Carson, J. J. Kim, J. A. Metcalf, and J. P. Cant. 2015a. Essential amino acid infusions stimulate mammary expression of eukaryotic initiation factor $2 \mathrm{~B} \varepsilon$ but milk protein yield is not increased during an imbalance. J. Dairy Sci. 98:44994508. https://doi.org/10.3168/jds.2014-9051.

Doelman, J., J. J. M. Kim, M. Carson, J. A. Metcalf, and J. P. Cant. 2015b. Branched-chain amino acid and lysine deficiencies exert different effects on mammary translational regulation. J. Dairy Sci. 98:7846-7855. https://doi.org/10.3168/jds.2015-9819.

Dong, X., Z. Zhou, L. Wang, B. Saremi, A. Helmbrecht, Z. Wang, and J. J. Loor. 2018. Increasing the availability of threonine, isoleucine, valine, and leucine relative to lysine while maintaining an ideal ratio of lysine:methionine alters mammary cellular metabolites, mammalian target of rapamycin signaling, and gene transcription. J. Dairy Sci. 101:5502-5514. https://doi.org/10.3168/jds.2017 $-13707$.

Dunshea, F. R., D. E. Bauman, E. A. Nugent, D. J. Kerton, R. H. King, and I. McCauley. 2005. Hyperinsulinaemia, supplemental protein and branched-chain amino acids when combined can increase milk protein yield in lactating sows. Br. J. Nutr. 93:325332. https://doi.org/10.1079/BJN20041366.

Foster, K. G., H. A. Acosta-Jaquez, Y. Romeo, B. Ekim, G. A. Soliman, A. Carriere, P. P. Roux, B. A. Ballif, and D. C. Fingar. 2010. Regulation of mTOR complex 1 (mTORC1) by raptor $\operatorname{Ser}^{863}$ and multisite phosphorylation. J. Biol. Chem. 285:80-94. https://doi .org/10.1074/jbc.M109.029637.

Giallongo, F., M. T. Harper, J. Oh, J. C. Lopes, H. Lapierre, R. A. Patton, C. Parys, I. Shinzato, and A. N. Hristov. 2016. Effects of rumen-protected methionine, lysine, and histidine on lactation performance of dairy cows. J. Dairy Sci. 99:4437-4452. https://doi .org/10.3168/jds.2015-10822.

Gingras, A.-C., B. Raught, S. P. Gygi, A. Niedzwiecka, M. Miron, S. K. Burley, R. D. Polakiewicz, A. Wyslouch-Cieszynska, R. Aebersold, and N. Sonenberg. 2001. Hierarchical phosphorylation of the translation inhibitor 4E-BP1. Genes Dev. 15:2852-2864.

Gu, X., J. M. Orozco, R. A. Saxton, K. J. Condon, G. Y. Liu, P. A. Krawczyk, S. M. Scaria, J. W. Harper, S. P. Gygi, and D. M. Sabatini. 2017. SAMTOR is an $S$-adenosylmethionine sensor for the mTORC1 pathway. Science 358:813-818. https://doi.org/10.1126/ science.aao3265.

Harlan, S. M., D.-F. Guo, D. A. Morgan, C. Fernandes-Santos, and K. Rahmouni. 2013. Hypothalamic mTORC1 signaling controls sympathetic nerve activity and arterial pressure and mediates leptin effects. Cell Metab. 17:599-606. https://doi.org/10.1016/j.cmet 2013.02.017.

Harrington, L. S., G. M. Findlay, and R. F. Lamb. 2005. Restraining PI3K: mTOR signalling goes back to the membrane. Trends Biochem. Sci. 30:35-42. https://doi.org/10.1016/j.tibs.2004.11.003.

Huynh, H. T., G. Robitaille, and J. D. Turner. 1991. Establishment of bovine mammary epithelial cells (MAC-T): An in vitro model for bovine lactation. Exp. Cell Res. 197:191-199. https://doi.org/10 .1016/0014-4827(91)90422-Q.

Inoki, K., Y. Li, T. Zhu, J. Wu, and K. L. Guan. 2002. TSC2 is phosphorylated and inhibited by Akt and suppresses mTOR signalling. Nat. Cell Biol. 4:648-657. https://doi.org/10.1038/ncb839.

Jefferies, H. B. J. 1997. Rapamycin suppresses 5'TOP mRNA translation through inhibition of p70 ${ }^{\text {s6k }}$. EMBO J. 16:3693-3704. https:// doi.org/10.1093/emboj/16.12.3693.

Kennedy, B. K., and D. W. Lamming. 2016. The mechanistic target of rapamycin: The grand conducTOR of metabolism and aging. Cell Metab. 23:990-1003. https://doi.org/10.1016/j.cmet.2016.05.009.

Kerestes, M., V. Faigl, M. Kulcsár, O. Balogh, J. Földi, H. Fébel, Y. Chilliard, and G. Huszenicza. 2009. Periparturient insulin secretion and whole-body insulin responsiveness in dairy cows showing various forms of ketone pattern with or without puerperal metritis. Domest. Anim. Endocrinol. 37:250-261. https://doi.org/10.1016/j .domaniend.2009.07.003.

Kim, C.-H., J.-J. Choung, and D. G. Chamberlain. 1999. Determination of the first-limiting amino acid for milk production in dairy cows consuming a diet of grass silage and a cereal-based supplement containing feather meal. J. Sci. Food Agric. 79:1703-1708. https: //doi.org/10.1002/(SICI)1097-0010(199909)79:12<1703::AIDJSFA424>3.0.CO;2-5.

Kimball, S. R., A. N. D. Do, L. Kutzler, D. R. Cavener, and L. S. Jefferson. 2007. Rapid turnover of the mTOR Complex 1 (mTORC1) repressor REDD1 and activation of mTORC1 signaling following inhibition of protein synthesis. J. Biol. Chem. 283:3465-3475.

Lapierre, H., G. E. Lobley, D. R. Ouellet, L. Doepel, and D. Pacheco. 2007. Amino acid requirements for lactating dairy cows: reconciling predictive models and biology. Pages 39-59 in Proc. Proceedings of Cornell Nutrition Conference for Feed Manufacturers, East Syracuse, NY. Cornell University, Ithaca, NY.

Lapierre, H., D. R. Ouellet, L. Doepel, G. Holtrop, and G. E. Lobley. 2008. Histidine, lysine and methionine: From metabolism to balanced dairy rations. Page 31 in Eastern Nutrition Conference of Animal Nutrition Association of Canada. Vol. 14-31. Animal Nutrition Association of Canada, Quebec, Canada.

Li, S. S., J. J. Loor, H. Y. Liu, L. Liu, A. Hosseini, W. S. Zhao, and J. X. Liu. 2017. Optimal ratios of essential amino acids stimulate $\beta$-casein synthesis via activation of the mammalian target of rapamycin signaling pathway in MAC-T cells and bovine mammary tissue explants. J. Dairy Sci. 100:6676-6688. https://doi.org/10 .3168/jds.2017-12681.

Liu, G. M., M. D. Hanigan, X. Y. Lin, K. Zhao, F. G. Jiang, R. R. White, Y. Wang, Z. Y. Hu, and Z. H. Wang. 2017. Methionine, leucine, isoleucine, or threonine effects on mammary cell signaling and pup growth in lactating mice. J. Dairy Sci. 100:4038-4050. https://doi.org/10.3168/jds.2016-11973.

Long, X., Y. Lin, S. Ortiz-Vega, K. Yonezawa, and J. Avruch. 2005. Rheb binds and regulates the mTOR kinase. Curr. Biol. 15:702713. https://doi.org/10.1016/j.cub.2005.02.053.

Ma, Q., S. Hu, M. Bannai, and G. Wu. 2018. L-Arginine regulates protein turnover in porcine mammary epithelial cells to enhance milk protein synthesis. Amino Acids 50:621-628. https://doi.org/ 10.1007/s00726-018-2541-7.

Mackle, T. R., D. A. Dwyer, K. L. Ingvartsen, P. Y. Chouinard, J. M. Lynch, D. M. Barbano, and D. E. Bauman. 1999. Effects of insulin and amino acids on milk protein concentration and yield from dairy cows. J. Dairy Sci. 82:1512-1524. https://doi.org/10.3168/ jds.S0022-0302(99)75378-6.

Mackle, T. R., D. A. Dwyer, K. L. Ingvartsen, P. Y. Chouinard, D. A. Ross, and D. E. Bauman. 2000. Effects of insulin and postruminal supply of protein on use of amino acids by the mammary gland for milk protein synthesis. J. Dairy Sci. 83:93-105. https://doi.org/10 .3168/jds.S0022-0302(00)74860-0.

Manning, B. D., and L. C. Cantley. 2003. Rheb fills a GAP between TSC and TOR. Trends Biochem. Sci. 28:573-576. https://doi.org/ 10.1016/j.tibs.2003.09.003.

Martineau, R., D. R. Ouellet, E. Kebreab, R. R. White, and H. Lapierre. 2017. Relationships between postruminal casein infusion and milk production, and concentrations of plasma amino acids and blood urea in dairy cows: A multilevel mixed-effects meta-analysis. J. Dairy Sci. 100:8053-8071. https://doi.org/10.3168/jds.2016 $-11813$.

Meijer, G. A. L., J. Van Der Meulen, J. G. M. Bakker, C. J. Van Der Koelen, and A. M. Van Vuuren. 1995. Free Amino Acids in Plasma and Muscle of High Yielding Dairy Cows in Early Lactation. J. Dairy Sci. 78:1131-1141. https://doi.org/10.3168/jds .S0022-0302(95)76730-3.

Menon, S., C. C. Dibble, G. Talbott, G. Hoxhaj, A. J. Valvezan, H. Takahashi, L. C. Cantley, and B. D. Manning. 2014. Spatial control of the TSC complex integrates insulin and nutrient regulation of mTORC1 at the lysosome. Cell 156:771-785. https://doi.org/10 .1016/j.cell.2013.11.049. 
Nascimento, E. B. M., M. Snel, B. Guigas, G. C. M. van der Zon, J. Kriek, J. A. Maassen, I. M. Jazet, M. Diamant, and D. M. Ouwens. 2010. Phosphorylation of PRAS40 on Thr246 by PKB/AKT facilitates efficient phosphorylation of Ser183 by mTORC1. Cell. Signal. 22:961-967. https://doi.org/10.1016/j.cellsig.2010.02.002.

Pösö, A. R., and L. A. Lindberg. 1994. Plasma protein synthesis and serum amino acids in dry and lactating dairy cows. Zentralbl. Veterinarmed A. 41:72-75.

Reho, J. J., D. F. Guo, and K. Rahmouni. 2019. Mechanistic target of rapamycin complex 1 signaling modulates vascular endothelial function through reactive oxygen species. J. Am. Heart Assoc. 8:e010662. https://doi.org/10.1161/JAHA.118.010662.

Rius, A. G., J. A. D. R. N. Appuhamy, J. Cyriac, D. Kirovski, O. Becvar, J. Escobar, M. L. McGilliard, B. J. Bequette, R. M. Akers, and M. D. Hanigan. 2010. Regulation of protein synthesis in mammary glands of lactating dairy cows by starch and amino acids. J. Dairy Sci. 93:3114-3127. https://doi.org/10.3168/jds.2009-2743.

Ruvinsky, I., and O. Meyuhas. 2006. Ribosomal protein S6 phosphorylation: From protein synthesis to cell size. Trends Biochem. Sci. 31:342-348. https://doi.org/10.1016/j.tibs.2006.04.003.

Sancak, Y., L. Bar-Peled, R. Zoncu, A. L. Markhard, S. Nada, and D. M. Sabatini. 2010. Ragulator-Rag complex targets mTORC1 to the lysosomal surface and is necessary for its activation by amino acids. Cell 141:290-303. https://doi.org/10.1016/j.cell.2010 .02 .024 .

Sarbassov, D. D., D. A. Guertin, S. M. Ali, and D. M. Sabaini. 2005. Phosphorylation and regulation of Akt/PKB by the Rictor-mTOR complex. Science 307:1098-1101. https://doi.org/10.1126/science .1106148 .

Schwab, C. G., L. D. Satter, and A. B. Clay. 1976. Response of lactating dairy cows to abomasal infusion of amino acids. J. Dairy Sci 59:1254-1270. https://doi.org/10.3168/jds.S0022-0302(76)84354 -8 .

Spector, I. M. 1974. Animal longevity and protein turnover rate. Nature 249:66. https://doi.org/10.1038/249066a0.

Swaisgood, H. E. 1995. Protein and amino acid composition of bovine Milk. Pages 464-468 in Handbook of Milk Composition. R. G. Jensen, ed. Academic Press, San Diego, CA.

Wang, L., T. E. Harris, R. A. Roth, and J. C. Lawrence Jr.. 2007. PRAS40 regulates mTORC1 kinase activity by functioning as a direct inhibitor of substrate binding. J. Biol. Chem. 282:2003620044. https://doi.org/10.1074/jbc.M702376200.
Wang, Q., and J. Holst. 2015. L-type amino acid transport and cancer: Targeting the mTORC1 pathway to inhibit neoplasia. Am. J. Cancer Res. 5:1281-1294.

Wolfson, R. L., L. Chantranupong, R. A. Saxton, K. Shen, S. M. Scaria, J. R. Cantor, and D. M. Sabatini. 2016. Sestrin2 is a leucine sensor for the mTORC1 pathway. Science 351:43-48. https:// doi.org/10.1126/science.aab2674.

Xu, L. B., M. D. Hanigan, X. Y. Lin, M. M. Li, Z. G. Yan, Z. Y. Hu, Q. L. Hou, Y. Wang, K. R. Shi, and Z. H. Wang. 2019. Effects of jugular infusions of isoleucine, leucine, methionine, threonine, and other amino acids on insulin and glucagon concentrations, mammalian target of rapamycin (mTOR) signaling, and lactational performance in goats. J. Dairy Sci. 102:9017-9027. https://doi .org/10.3168/jds.2018-16102.

Yoder, P. S., T. Ruiz-Cortes, J. J. Castro, and M. D. Hanigan. 2019. Effects of varying extracellular amino acid profile on intracellular free amino acid concentrations and cell signaling in primary mammary epithelial cells. J. Dairy Sci. 102:8977-8985. https://doi.org/ $10.3168 /$ jds.2018-16122.

Zhang, J., Z. Gao, and J. Ye. 2013. Phosphorylation and degradation of S6K1 (p70S6K1) in response to persistent JNK1 Activation. BBA Mol. Basis Dis. 1832:1980-1988.

Zhao, K., W. Liu, X. Y. Lin, Z. Y. Hu, Z. G. Yan, Y. Wang, K. R. Shi, G. M. Liu, and Z. H. Wang. 2019. Effects of rumen-protected methionine and other essential amino acid supplementation on milk and milk component yields in lactating Holstein cows. J. Dairy Sci. 102:7936-7947. https://doi.org/10.3168/jds.2018-15703.

Zhou, Y., Z. Zhou, J. Peng, and J. J. Loor. 2018. Methionine and valine activate the mammalian target of rapamycin complex 1 pathway through heterodimeric amino acid taste receptor (TAS1R1/ TAS1R3) and intracellular $\mathrm{Ca}^{2+}$ in bovine mammary epithelial cells. J. Dairy Sci. 101:11354-11363. https://doi.org/10.3168/jds .2018-14461

\section{ORCIDS}

Virginia L. Pszczolkowski ำ https://orcid.org/0000-0001-6476-6214 Sebastian I. Arriola Apelo (ㄴ https://orcid.org/0000-0003-0274-5367 